\title{
QUAL É O LUGAR DA FORMAÇÃO HUMANA NAS POLÍTICAS CURRICULARES CONTEMPORÂNEAS?
}

\author{
Geniana dos Santos \\ Universidade Federal de Mato Grosso - UFMT \\ Denise de Souza Destro \\ Rede Municipal de Educação em Juiz de Fora - MG
}

\begin{abstract}
Resumo
Este texto discute os significantes vazios nas políticas educacionais endereçadas à Educação Básica (EB) a partir da Base Nacional Comum Curricular (BNCC), dialogando com autores do campo curricular que problematizam os sentidos de crise e qualidade na educação que subsidiam o contexto reformista. Propõe-se, assim, a reflexão sobre as diferentes práticas discursivas a respeito das crises de paradigmas educacionais entrecruzando-se com discursos que problematizam a projeção de tipos humanos nas produções curriculares, conectando sentidos como formação humana e humanismo. Destaca-se a virada do pensamento pedagógico que se antagoniza, principalmente, ao discurso da decodificação das habilidades e competências, atualmente emergente nas políticas de currículo para EB, ressaltando as articulações que possibilitaram a significação de currículo como política cultural. Como superfície de análise e reflexão, elegemos o discurso da BNCC no tocante à formação, ao desenvolvimento integral e às habilidades socioemocionais apresentados como princípios humanizadores para o currículo visando ao desenvolvimento global.
\end{abstract}

Palavras-chave: Cidadania. Formação Humana. Política Curricular. Significantes Vazios. Perspectiva discursiva.

\begin{abstract}
This text discusses the empty signifiers in educational policies addressed to Basic Education (EB) from the Common National Curriculum Base (BNCC), dialoguing with authors from the curriculum field that problematize the meanings of crisis and quality in education that support the reformist context. Thus, it is proposed to reflect on the different discursive practices on the crises of educational paradigms intersecting with discourses that problematize the projection of human types in curriculum productions, connecting meanings such as human formation and humanism. The turning point of pedagogical thinking stands out, which is mainly antagonized by the discourse of the decoding of skills and competences, currently emerging in the curriculum policies for EB, highlighting the articulations that made possible the meaning of curriculum as a cultural policy. As a surface for analysis and reflection, we chose BNCC's discourse on training, integral development and socio-emotional skills presented as humanizing principles for the curriculum aiming at global development.
\end{abstract}

Keywords: Citizenship. Human Formation. Curriculum Policy. Significant empty. Discursive perspective.

ISSN 1645-1384 (online) www.curriculosemfronteiras.org 


\section{Introdução}

Este texto discute os significantes vazios, expressões de força articulatória, nas políticas educacionais endereçadas à Educação Básica (EB) a partir da Base Nacional Comum Curricular (BNCC). Para tal, tencionamos dilucidar como discursos prescritivos projetam intencionalidade(s) educativa(s), refletindo sobre o lugar da formação humana nesse enredo.

Para interpretar uma dada estrutura discursiva em torno da formação humana e da cidadania, evidenciamos momentos articulatórios distintos, tanto epistemológicos quanto pragmáticos, visto que projetam uma ameaça, crise humana a ser contida pela educação. Desse modo, destacamos o relatório organizado por Edgar Faure já em 1972, Aprender a Ser, ampliado e ressignificado na década de 90, por Jacques Delors, mediante o documento Educação: um tesouro a descobrir, financiado pelo Banco Mundial; e, atualmente, a BNCC e sua proposta de formação integral, via valorização do conhecimento e construção de competências.

Esses documentos destacam o princípio da formação ao longo da vida, sob um enfoque humanista, todavia entrelaçado à lógica instrumental da organização social e do trabalho, com vistas ao desenvolvimento econômico. Assim, ainda que reconheçamos as contribuições, enquanto contexto de influência, na produção de debates, enfrentamentos e a estruturação das políticas educacionais brasileiras, materializadas na LDB 9394/96, Parâmetros Curriculares Nacionais e Diretrizes Nacionais, é preciso admitir que formação humana e cidadania, além de formação ao longo da vida, foram expressões significantes vazias, logo, passíveis de deslocamentos para outros significantes e disputas por diferentes grupos de interesses.

Nesse sentido, ponderamos que toda ação é política, contudo, entendemos que nem toda política está comprometida com pressupostos defensáveis, ou seja, nem sempre promovem justiça social e democracia. A reflexão supramencionada é relevante para não desgastarmos/banalizarmos o fazer político como um fazer discursivo ou mero ato retórico.

Isto posto, ressaltamos que a política expressa um processo articulatório em torno de demandas emergentes, as quais são responsáveis por uma pausa entre as diferenças (Laclau, 2015). Toda ameaça corporifica uma narrativa horrífica que se encarna em um mal tangível, neste caso, negligência em face de direitos educacionais/crise social e na educação, mobilizando a subjetivação de grupos de sujeitos que, interpelados, buscam combater o horror enunciado (Clarke, 2015), estejam tais sujeitos nas escolas, nas secretarias de educação ou em grandes corporações.

Neste trabalho, discutimos como o projeto moderno e pretensamente democrático de desenvolvimento integral está estruturado discursivamente no processo articulatório que sustenta a BNCC, diferenciando-se substancialmente da formação humana proposta em outros momentos discursivos sobre a educação. Para isso, é relevante observarmos alguns termos que ora são mobilizados em substituição/rasura e suplementação, que parecem significar o mesmo, mas também outros sentidos.

Tendo em vista o contexto hodierno e as práticas discursivas que projetam um "novo currículo” desde a Educação Infantil até o Ensino Médio, a perspectiva discursiva procura 
escrutinar a produção de sentido como estrutura da produção política, ação continuamente potente para mobilizar abordagens de pesquisa em educação, bem como de construção de estratégias para potencializar um currículo humanizador nos âmbitos escolares perante contextos conservadores.

Conforme assinalam Oliveira e Lopes (2011, p. 21-28),

[...] política cultural é uma luta discursiva pela constituição de representações que envolve negociação, isto é, articulação discursiva na qual alguns grupos sociais particulares buscam defender determinadas demandas curriculares e para tal constituem representações. É com esta significação de currículo, em que se confere centralidade aos conceitos de poder e de cultura, que conectamos os aportes teóricos-metodológicos de Stephen Ball à teoria de discurso de Ernesto Laclau.

A política curricular nesta discussão é entendida como prática de significação e, portanto, política cultural. A formação cidadã/humana, por conseguinte, está traduzida como formação cultural que compreende demandas circunscritas por contingências, precariedades e necessidades produzidas no âmbito social. Desse modo, este texto está assinalado por uma interpretação da política que tem procurado desconstruir essencialidades presentes no discurso que fixa identidades/estereótipos (Bhabha, 2013; Lopes, 2014, 2015), ao passo que sinaliza sentidos potentes à Educação Básica pública.

O que ora pode ser entendido como essencialização da identidade é sublinhado pela distinção de representações definidas mediante perspectivas psicológicas, que destacam o desenvolvimento humano crivado por condições endógenas e exógenas ao indivíduo, como domínio da linguagem, do repertório de um bem comum, com vistas à assimilação de bens simbólicos/ilustração e superação de desigualdades sociais para futura inserção no meio laboral.

No tocante a esse aspecto, as avaliações de larga escala corroboram para a projeção de tipos humanos enquanto projetos escolares/curriculares, nem sempre condizentes com o vivenciado pela escola, embora tenham se tornado produtores de discursos curriculares que regulam a atuação docente no âmbito da ensino-aprendizagem (Popkewitz, 2013), reforçando, portanto, a ideia de uma crise sem precedentes na educação.

A padronização de identidades, nesse sentido, para a criança e para o adolescente, produz a anulação, o silenciamento do que as crianças são, do que os jovens são, privilegiando o que ambos devem ser, algo que confronta seriamente qualquer fundamento humanista. Essa projeção, ainda que necessite ser repensada constantemente pelos sujeitos que atuam no contexto educacional, não consiste em projeto novo.

Conforme assinalam Lessard e Carpentier (2016), desde o pós-guerra, as Nações Unidas buscam alinhar um projeto educacional baseado no ideário de formação humana, na socialização e na superação da barbárie por meio do desenvolvimento econômico e social, tendo o Holocausto como episódio histórico a ser negado pelo seu caráter horrífico. Tal movimento culmina em projetos de expansão da escolarização, principalmente em países em 
desenvolvimento, como é o caso do Brasil, gerando bandeiras de democratização do conhecimento e da formação humana.

A significação de uma escola cuja intencionalidade formativa se pauta na formação ética, política e estética, traz a validade inquestionável de uma formação para a vida, delineando uma compreensão universalizada que associa atitudes, procedimentos e conhecimentos escolares às bandeiras progressistas, entendidas como princípios elementares à modernidade.

Neste trabalho, tencionamos escrutinar as articulações que fixam tais discursos como postulados universais, refletindo se cidadania e formação humana são significantes entendidos como procedimento ou instrumento para outros fins educativos/sociais. Nesse bojo, cabe questionar, outrossim, o que tais discursos condensam e o que eles barram nas políticas educacionais normatizadoras vigentes, como se expandem e o que ou quem silenciam.

\section{Práticas discursivas e processos de articulação em torno da humanização}

O processo articulatório em resposta à crise humana, condensada pelo sentido de ensino tradicional, aglutinou diferentes práticas discursivas que incitavam a transformação paradigmática em educação (Ausubel, 1963, 1976; Apple e Beane, 2001; Apple, 2006; Tadeu e Moreira, 2013). Alguns espectros de teorias sobre uma educação para todos foram resgatados e ressignificados nesse processo.

A mudança paradigmática da década de 1970, em que se faz a passagem de uma abordagem tecnológica e burocrática para uma abordagem humanista, é um passo significativo para que os teóricos do currículo, reunidos na abrangente designação de teorias críticas, passem a analisar e compreender a educação à luz de outros critérios conceituais (Pacheco, 2009, p. 392).

A noção de aprendizagem significativa (princípios da assimilação ativa e da acomodação), denominada similarmente de conhecimento prévio, reposicionou a aprendizagem como um ato cognitivo, mas dependente da vivência cultural, capaz de propiciar a formação autônoma e emancipatória. Isto posto, enfatizamos a pertinência em identificar a hibridação teórica para esse período, tão estranha quanto necessária para impulsionar a mudança de paradigma educacional.

Tendo como contexto o fim da ditadura brasileira, podemos destacar a vivência de uma censura que regulava a produção do conhecimento científico, bem como o início de uma discussão curricular que negava o racionalismo técnico, as transposições teóricas descontextualizadas, os pressupostos de uma psicologia cognitiva, mecanicista e funcionalista (Freire, 1989).

Se é verdade que nesse período a UNESCO já investia na formação humana como tema para a educação escolar, conforme disposto no documento Aprender a Ser, inspirado nas produções da terceira força da psicologia, como a Psicologia do Ser de Maslow, no Brasil, 
tais discussões ainda se mostravam vivas apenas nas produções acadêmicas de perfil crítico, fenomenológico, marxista, com Freire, Silva entre outros.

Nessa época, com a abertura do país e a virada do pensamento educacional brasileiro, vivenciamos a valorização das práticas de vida que adentram no contexto escolar, ressignificando esse espaço como parte da vida humana e não como ambiente racional e técnico, classificatório e excludente como anteriormente postulado. Em muito, tais problematizações ecoavam em outros países a partir de uma onda humanista de tendência liberal e de perfil individualista (Candau, 1983).

Nesse sentido, a lógica da democratização, do acesso e da luta pela transformação do cenário educacional potencializou a formação de novas concepções de ensinar e aprender, coadunando diferentes discursos, especialmente no campo da ainda hegemônica psicologia, da filosofia existencialista-fenomenológica e do Marxismo, filiados a outras diversas e contraditórias matrizes teóricas (Silva, 1981); (Freire, 1982). Esse truncado contexto epistemológico denota de forma emblemática o hibridismo e a suplementação de uma cadeia articulatória em prol da formação humana para a cidadania que, para existir, necessitava confrontar e negar a escola excludente da época, denotando que o processo articulatório não desfaz diferenças, mas sobretudo colocam-nas pausadas em face de um antagonismo a ser vencido.

A mudança de práticas discursivas é pontuada por Pacheco (2009) como um fenômeno ligado às formas de entender o mundo, o homem e, por conseguinte, a sua formação. Para o autor, que ainda contrapõe teorias da instrução às teorias críticas no âmbito do currículo, problematizando a centralidade do conhecimento, o humanismo passa a ser focalizado enquanto meio de tornar a educação mais igualitária.

Isso pois, nessa prática discursiva, a política educacional deve ser direcionada, e sentidos de formação devem acolher não somente o saber técnico que tende a ser instrumental, funcionalista, com vistas à adequação social, à lógica econômica ou cultural, sem, contudo, negociar o que pode ser entendido como cultural.

Para Azevedo (2007, p. 20), faz-se necessária uma política de formação que focalize o humano, com vistas à transformação social.

Se o objetivo de nossa política educacional é formar cidadãos humanistas, minha discussão pode fazer algum sentido. Esclareço que por humanismo refiro-me simplesmente à visão do homem como um ser eminentemente social, com determinadas potencialidades e limites, um ser expressivo, emotivo, criativo e efêmero, capaz de construir linguagens e símbolos e de transformar a natureza e a sociedade.

Existem inúmeras formas de significar a cidadania e o humanismo, lançando sentidos possíveis para formação humana, fundamentados por diferentes correntes/abordagens humanistas ou humanizadoras. O humanismo radical enquanto abordagem assinala o homem enquanto construtor de si, nega a possibilidade da subjugação ao outro e está alicerçado no sentido de liberdade. Esse tipo de compreensão radical é algo contraditório a um projeto de 
formação institucionalizada, trazendo vários tipos de dificuldades de operacionalização das práticas formativas dos sujeitos.

O humanismo como princípio associado à escola é radicalmente impossível, isso pois esta compreensão de homem e de mundo, que está situada em um fundamento de desenvolvimento humano endógeno ao ser, é sobretudo, uma compreensão aberta, não diretiva, baseada em pilares como a consideração positiva incondicional, a tendência atualizante, esta traduzida nas políticas educacionais a partir da expressão: aprender a aprender e, na BNCC, como a primeira competência, que enfatiza a capacidade de um sujeito continuar aprendendo.

Além disso, a empatia e a congruência, categorias centrais ao humanismo, embora sejam necessárias enquanto propósito, princípio educativo, não podem ser direcionadas como prevê a formação escolar proposta pela BNCC, já que ela se insere na lógica da pedagogia dos domínios desenvolvida por Bloom para a racionalização dos processos cognitivos básicos.

\section{Contribuições da Teoria do Discurso para a compreensão do contexto reformista}

A Teoria do Discurso possibilita compreender a demanda nomeada formação humana com vistas à cidadania como uma proposta potente no contexto da formação escolar, mas ainda assim permeada de identidades plenas, algo impossível em sua completude, mas necessário enquanto sentido de luta pela intencionalidade pedagógica projetada à Educação Básica.

Um caráter necessário que transforma e afeta processos de subjetivação, mediante identificação/estranhamento/reconhecimento; impossível, pois estará sempre em negociação constante, em disputa sobre como formar e o que é necessário para formar o cidadão crítico, desde os primeiros anos da formação escolar. Esses aspectos tornam qualquer projeto educacional hegemônico, provisório e passível de transformação a ser debatido e negociado junto aos sujeitos escolares para construção democrática da intencionalidade educativa.

Tendo em vista tais aspectos, é relevante ter em mente, conforme assinalam Gauthier e Tardif (2014, p. 26) que:

[...] o humanismo pode ser visto como um prolongamento natural do racionalismo, pois situa justamente o homem no centro do discurso, da cultura, para transformá-lo no sujeito, no ator principal do conhecimento. É impossível discutir racionalmente com o semelhante se ele não é reconhecido como um igual que merece respeito. Além disso, o humanismo - como o racionalismo - está baseado na convicção de que os seres humanos são capazes de subtrair-se à violência, aos preconceitos, às coações, e determinar-se graças à sua própria força interior, à sua razão. O humanismo repousa sobre o princípio de que o ser humano não é uma coisa, um objeto, um ser determinado uma vez por todas, um animal adestrado e condicionado para todo o sempre pela sua genética ou pelo seu meio; pelo contrário, ele considera o ser humano como um "ser aberto", cuja natureza 
não é definida antecipadamente e de uma vez por todas, um ser capaz de modificar-se, transformar-se, melhorar-se. Em suma, o humanismo considera o homem como um ser perfectível por sua própria ação: cada um de nós pode se tornar melhor.

Para os autores, esse paradigma humanizador se apoia em uma compreensão de cultura que assinala, enquanto fundamento, uma problematização da autoridade de qualquer fundamento. Nesse sentido, a radicalização dessa demanda prescinde da negociação, em outros termos, do diálogo entre os sujeitos do processo educativo, do ensino-aprendizagem, simplificado como formação para a cidadania, ou seja, para o estar e viver junto.

Ainda segundo os autores,

[...] todos os modelos, todos os valores, todas as crenças, todos os saberes - pouco importando a sua antiguidade, a sua dignidade, a sua divindade, a sua autoridade, o seu poder ou a sua violência - são e devem ser submetidos à livre discussão entre as pessoas (Gauthier e Tardif, 2014, p. 26).

Embora consideremos potente a demanda por formação humana, sinalizamos que a escolarização pressupõe procedimentos que estão relacionados à cultura escolar e a conhecimentos que articulam a comunidade e a sociedade, sendo imprescindível pluralizar o espaço de negociação do que seja humano ideal a ser formado na escola, sinalizando para quais conhecimentos podem contribuir para a formação cidadã, reflexiva, ética, estética e política. Nesse ponto, também destacamos que o humanismo como extensão do racionalismo compromete a ampliação da desestabilização dos modelos supracitados, pois seus pressupostos se sustentam em categorias que não se associam diretamente com os propósitos da escolarização.

Essa ambivalência acaba por provocar práticas discursivas entendidas como concorrentes, quando deveriam ser equivalentes. A primeira atrela formação escolar com a formação cidadã, sem ao certo definir o que tal significado expressa, e a segunda defende a formação escolar como aquela capaz de produzir um sujeito competente para atuação no mundo, restringindo a funcionalidade da escola ao campo do trabalho.

Nesse sentido, cabe resgatar Laclau (2015), que assegura que a posição da Teoria do Discurso não é incompatível com o humanismo.

O que rejeitamos é a ideia de que valores humanistas tenham o status metafísico de uma essência e que sejam, portanto, anteriores, a qualquer história e sociedade concretas. Contudo, isso não é para negar sua validade. Só significa que sua validade é construída por meio de práticas discursivas e argumentativas particulares (Laclau; Mouffe, p. 66).

A partir de Bhabha (2013, p. 74), consideramos que problematizar tais contradições seja potencializador para a política educacional, uma vez que, conforme o autor, 
É apenas quando compreendemos que todas as afirmações e sistemas culturais são construídos nesse espaço contraditório e ambivalente da enunciação que começamos a compreender por que as reivindicações hierárquicas de originalidade ou "pureza” inerentes às culturas são insustentáveis, mesmo antes de recorrermos a instâncias históricas empíricas que demostram seu hibridismo.

Nesse sentido, uma proposta pedagógica orientada pela teoria humanista seria em sua propositura pós-colonial, pois desestabilizaria sentidos de colonização como a própria ideia de formação exógena ao sujeito e colocaria em revisão o fato de a escola realizar a formação (humana), mesmo ela sendo o espaço privilegiado para negociação e não negação de identidades (Bhabha, 2013).

Cabe entender, para isso, que não há nenhum problema em escolarizar os sujeitos a partir de conhecimentos sociais considerados importantes para compor o repertório escolar, desde que sejam continuamente repensadas as lutas assimétricas que fixam tais conhecimentos nas propostas curriculares endereçadas à EB e, principalmente, o quanto há de humanização nos processos de formação escolar. Nesse sentido, formar o cidadão na escola é, também, não furtar da escola o papel de escolarizar/ensinar, em nome de uma formação crítica e cidadã.

Tais reflexões incidem em considerar que a formação humana, nesse entender, pode tanto significar uma formação ilustrada, para um posicionamento privilegiado no mundo do trabalho moderno, quanto uma formação para o desempenho de atividade que não esteja circunscrita às regras da atividade laboral. Outrossim, pode significar ainda a formação para convivência pacífica, para o cumprimento de obrigações com a comunidade, entre outros sentidos colocados em pauta no âmbito das políticas educacionais. Contudo, salutar se faz observar que em todos os sentidos possíveis à formação humana, nenhum pode ser totalizador, único, fixo e definitivo, visto que será sempre parcial e contingente.

\section{Significantes vazios e sua relevância para as políticas: contribuições da Perspectiva Discursiva}

O significante vazio pode ser definido como uma totalidade fracassada, conforme define Laclau (2011, p. 68), pois surge da impossibilidade de significação, que se mostra como uma interrupção, subversão na estrutura do signo.

Essa totalidade constitui um objeto ao mesmo tempo impossível e necessário. Impossível porque a tensão entre equivalência e diferença é, em última instância, insuperável; necessário porque sem alguma espécie de fechamento, por mais precário que possa ser, não haveria significação nem identidade (Laclau, 2013, p. 119).

Cada significante vazio, desprovido de um conteúdo fechado, será um nome capaz de articular diferentes demandas, de representá-las, sendo um momento de descanso, de trégua das relações diferenciais em resposta a uma ameaça antagônica, isso tende a posicionar uma 
particularidade privilegiada na cadeia de significação. Nesse entender, toda tentativa de universalização torna o objeto demandado impossível, uma vez que, para assumir o lugar hegemônico, a particularidade que constituía determinada demanda precisa deixar de existir (Laclau, 2011, 2013, 2015).

É nesse sentido que a Teoria do Discurso permite compreender de forma satisfatória a formação humana e cidadã como elementos que compõem uma intencionalidade educativa projetada à escola, com dissonantes compreensões de mundo, homem e sociedade.

Na Teoria do Discurso, as demandas mobilizam a produção de articulação, estando elas sempre em confronto à ameaça. No entendimento de Laclau, são as demandas que possibilitam os processos de identificação e estes serão estruturados pela relação de diferença e equivalência em que há oposição a algo ou alguém.

Demanda pode ser conceituada em psicanálise como “[...] forma comum de expressão de um desejo, quando se quer obter alguma coisa de alguém, a partir da qual o desejo se distingue da necessidade” (Chemama, 1995, p. 40). Entretanto, faz-se necessário considerar que, em psicanálise lacaniana,

[...] deve-se observar que a noção de demanda não pode ser entendida apenas no nível das representações triviais que o termo, aparentemente muito banal, poderia sugerir. Este assumiu, em particular, um sentido específico na teoria de Lacan, sentido que o uso cotidiano que se faz dele em geral dá a entender, mas que também dissimula. J. Lacan introduziu a noção de demanda, apontando-a à de necessidade. O que especifica o homem é que ele depende, para suas necessidades mais essenciais, de outros homens, aos quais o liga o uso em comum da palavra e da linguagem. [...] ora, quando o sujeito se coloca na dependência do outro, a particularidade a que visa a sua necessidade fica, de certa forma, anulada (Chemama, 1995, p. 40).

Nessa perspectiva, destacamos a necessidade da relação, da negociação, uma vez que, somente nesse contexto as demandas são possíveis (demanda-se em direção a algo ou alguém), tornando possível também a existência de um sujeito que emerge em resposta ao outro que o interpela. Segundo Chemama (1995, p. 40),

[...] o mundo humano impõe ao sujeito demandar, encontrar palavras que serão audíveis pelo outro. É no mesmo endereço que constitui esse Outro, escrito com O maiúsculo, porque essa demanda que o sujeito lhe dirige constitui seu poder, sua influência sobre o sujeito.

Em psicanálise as demandas são adjetivadas, uma vez que no processo de dependência imposto pela relação, a particularidade objetivada acaba por ser anulada frente ao outro. Isso implica afirmar que, mesmo existindo uma demanda específica, uma reivindicação por determinado objeto, ela não será central quando a referida relação existir. Já em Laclau (2011, 2013, 2014), a demanda consiste em unidade mínima de significação em torno da qual se formula um processo articulatório. 
Essa dinâmica pode ser entendida visto que "O sujeito vive num mundo em que suas necessidades são reduzidas ao valor de troca” (Quinet, 2011, p. 90). Diferenciando necessidade de demanda, o autor discute que a primeira está ligada ao contexto primitivo das condições de existência, enquanto a segunda é redimensionada pelo simbólico quando o mesmo, por meio da palavra, coloca o sujeito e um sistema de significantes. Algo que encontra semelhança às proposituras de Maslow em sua Psicologia do Ser.

Para Quinet (2011, p. 96),

A demanda do sujeito provém do Outro, sendo datada do lugar do Outro, lugar originalmente ocupado pela mãe, e o desejo é articulado através da demanda, transparecendo na enunciação dos significantes, onde se articula o desejo como efeito metonímico, na medida em que este passa de um para outro significante rolando como um dado lançado na fala. De palavra em palavra, temos o desejo como efeito metonímico da demanda.

Assim, a partir da perspectiva discursiva, a demanda não precisaria ser classificada ou adjetivada, como parece ser necessário em uma estrutura mais comprometida com a análise psicanalítica. Isso pois, dificilmente, em uma perspectiva que pretende compreender a dinâmica política, conseguiríamos essencializar sobre a natureza de uma demanda, se de amor ou de reconhecimento.

A partir de Laclau, é possível entender que as demandas constituem a condição de possibilidade de processos de identificação, elas tanto serão responsáveis pela articulação, expressa na disposição em participar dos jogos de linguagem, quanto viabilizarão a identificação, processo a partir do qual um determinado sujeito abre mão de suas particularidades (seu objeto particular demandado) na tentativa de assumir um ideal maior, expresso por um símbolo, um nome que "[...] se exerce no plano do reconhecimento" (Lacan, 1975, p. 291). Para Laclau (2011), um significante vazio, que, na cadeia significante poderia ser representado pela noção de universal.

Tendo em vista aquilo que se pensa sobre o significante vazio e o sujeito, Laclau (1985, 2014) possibilita entender que existe um adiamento das demandas dos sujeitos inscritos na cadeia de significação, tal característica da estrutura significante incide em um processo de contiguidade, conceituado na Teoria do Discurso como deslocamento. Nesse sentido é que podemos afirmar que o sujeito estará sempre adiado, emergindo apenas enquanto tal a partir de processos decisórios. Além disso, está aí a força de um significante vazio ou expressão significante que parece nada dizer, mas que pode, em um processo articulatório, condensar demandas de diferentes grupos sociais, possibilitando articulação em face de uma ameaça.

Nesses processos, diversas estratégias são estabelecidas, como o deslocamento, por exemplo. Segundo dicionário técnico de psicanálise, o deslocamento pode ser definido como:

Operação característica dos processos primários, por meio da qual uma quantidade de afetos se desprende da representação inconsciente, a qual está ligada, indo ligar-se a uma outra, cujos vínculos com a anterior são vínculos associativos pouco intensos ou, mesmo, contingentes. Esta última representação 
recebe, então, uma intensidade de interesse psíquico desproporcional em relação àquela que normalmente deveria comportar, enquanto que a primeira, desinvestida, fica como que recalcada (Chemmama, 1995, p. 46).

A partir desse conceito, a diferença passa a ser ressaltada e, ao mesmo tempo, convertese em equivalência capaz de mobilizar articulação. Lopes e Mendonça (2013, p. 13), sinalizando para uma compreensão mais ampla de demanda, atrelando-a às categorias de âmbitos deliberativos explicam que:

[...] demanda pode ser um pedido ou uma reivindicação (algo mais grave, tendo em vista o não acolhimento do pedido inicial). Na primeira forma, a demanda é apenas uma solicitação diretamente feita aos canais institucionais formais. Por exemplo, a ausência de uma escola num determinado bairro pode ensejar tal pedido à municipalidade. Se a escola é construída, o problema termina e a demanda se exaure. $\mathrm{O}$ atendimento da demanda se dá no plano administrativo, instância em que opera a lógica da diferença, no sentido expresso por Laclau.

Ainda acerca da formação de demandas potencializadoras para articulação, mesmo entre diferentes posicionamentos, os autores destacam que a frustração das demandas tende a possibilitar uma abertura na cadeia articulatória e, nesse sentido, provocar uma relação mais estreita entre as demandas, sempre equivalenciais (Lopes e Mendonça, 2013).

Para Laclau (2013, p. 129), nem todas as demandas podem ser consideradas democráticas, uma vez que permanecem isoladas em relação ao processo de equivalência. Outra consideração significativa feita pelo autor refere-se ao processo de articulação em que uma diversidade de demandas é frustrada e suprimida.

No bojo dessas considerações, situamos a demanda formação humana e cidadã como projeto social endereçado à escola, discutindo suas potencialidades e limitações, além de seu deslocamento por meio de significantes que querem dizer sempre outra coisa, em um caráter associativo e combinatório, todavia, pautado na dinâmica e lógica das diferenças.

\section{BNCC e Currículos de Referência: sentidos postos em rasura}

A produção da BNCC expressou um longo processo de negociação e dissenso no cenário educacional brasileiro, com o que pode ser considerada uma quarta versão, após aprovação do Conselho Nacional da Educação, normatizou e fixou o currículo por competências para todo o território brasileiro, independente da forma de organização curricular dos estados e municípios, por série ou ciclos, a BNCC propõe uma organização curricular anual e por habilidades (Brasil, 2017).

Embora estivesse prevista na Constituição de 1988, muitas foram as articulações instauradas ante e pró base, estas diziam respeito desde a concepções de educação postuladas quanto à maneira como o "novo currículo" chegaria às escolas. Com a homologação em 2017, os estados iniciaram o processo de construção dos seus documentos de referência 
curricular, sem a possibilidade de suprimir nenhum elemento disposto na base, mas com a “autorização” para acrescentar especificidades de sua realidade educacional.

Enquanto processo, esse primeiro ciclo pós base (2018) contou com a estratégia dos regimes de colaboração, em que estados e municípios trabalharam junto às equipes formadas nas secretarias locais para construção da sua versão de Currículo de Referência. O segundo ciclo pós base (2019) é caracterizado pelo processo de implementação, com orientações sobre as propostas pedagógicas dos municípios e, outrossim, para os Projetos Políticos Pedagógicos das Escolas (Brasil, 2018).

Um terceiro ciclo está previsto (2020) em que o processo de implementação, conforme denominado pelo MEC, acontecerá nas escolas por meio do acompanhamento das secretarias locais. Alguns estados estão caminhando no ritmo imposto pelo Ministério da Educação, enquanto outros ainda estão em vias de aprovar seus documentos de referência junto aos seus respectivos Conselhos Estaduais de Educação.

As temáticas e demandas mais abordadas nesse "novo currículo" têm sido os direitos de aprendizagem e desenvolvimento, desenvolvimento humano integral, as competências gerais (10), as por área de conhecimento, variando de 7 a 8, e as por componente curricular, igualmente de 7 a 8 . Além disso, são apresentadas as habilidades socioemocionais apagadas em toda a discussão sobre a base, mas em tela após tantas críticas sobre o caráter prescritivo dos currículos e o não lugar da formação humana nessa propositura. As habilidades socioemocionais resgatam, sobremaneira, a necessidade de uma formação que ultrapasse o caráter cognitivo das habilidades, dando abertura para que novas articulações sejam possíveis em torno da formação humana.

O primeiro desafio, contudo, nessa instância de escritura curricular, é conceber que existam habilidades “cognitivas” e habilidades não cognitivas, por serem adjetivadas de outro modo, conforme sugere o excerto a seguir.

Na BNCC, competência é definida como a mobilização de conhecimentos (conceitos e procedimentos), habilidades (práticas, cognitivas e socioemocionais), atitudes e valores para resolver demandas complexas da vida cotidiana, do pleno exercício da cidadania e do mundo do trabalho (Brasil, 2017, p. 8).

A divisão entre habilidades cognitivas, socioemocionais e híbridas, embora cause estranheza, tendo em vista que as emoções, do ponto de vista teórico, são outrossim, cognitivas, parte de releituras de campos da psicologia e da administração (Goleman, 1999), quando trazem conceitos como inteligência emocional, lócus de controle e empatia, conforme orientação do CONSED, 2017.

Tais categorias tendem a provocar a compreensão do que é central ou acessório na produção curricular proposta a partir da BNCC em que as linguagens jurídica, psicológica e administrativa se entrelaçam para sustentar práticas discursivas sobre a função da escola em garantir a cidadania e o desenvolvimento integral e, sobretudo, para afastar a ameaça/o antagonismo de uma crise educacional/de aprendizagem nunca antes vista. 
A intencionalidade da escola é a intencionalidade social, nessa perspectiva, alguns termos se mostram sob rasura, como a intencionalidade formativa presente nos documentos curriculares produzidos na década dos 90, agora traduzidos como intencionalidade educativa, pensada especialmente para a Educação Infantil: “[...] impõe a necessidade de imprimir intencionalidade educativa às práticas pedagógicas na Educação Infantil, tanto na creche quanto na pré-escola” (Brasil, 2017, p.38).

Formação humana, expressão tão desgastada do ponto de vista pragmático, às vezes devido a sua completa indefinição, está presente somente duas vezes em um documento de 600 páginas, mesmo que com seu sentido apensado em outras expressões como desenvolvimento (global/integral), direitos (126 vezes) de aprendizagem e ao desenvolvimento.

Isso denota o viés assumido pela BNCC de que a formação se dá pelo acesso (ao repertório cultural estabelecido) aos direitos de aprender e se desenvolver, anteriormente à BNCC, negligenciado aos sujeitos em escolarização nos contextos escolares brasileiros, conforme indicam os resultados das avaliações de larga escala.

\section{Considerações finais}

Este trabalho tencionou refletir sobre o processo articulatório que constitui a BNCC e projeta sentidos para a Educação Básica pública no Brasil, via homologação desde 2017. Para isso, focalizamos os significantes vazios e expressões que operam em semelhança, conforme definido por Laclau (2015). Nesta oportunidade, reiteramos que os significantes vazios não consistem em termos sem importância, mas sim em potência motriz capaz de articular diferenças e, por vezes, posicionamentos contrários/contraditórios, em uma cadeia discursiva.

Na política curricular analisada, destacamos como significantes vazios: direitos de aprendizagem e desenvolvimento; desenvolvimento integral (em outros momentos históricos, lidos como formação humana); competências (conhecimento em ação); habilidades (cognitivas, sendo compostas pelo processo cognitivo indicado por um verbo, objeto de conhecimento/conteúdo e procedimentos, e contexto de aplicação do conhecimento apreendido) e socioemocionais (que abrangem qualidades necessárias para a formação de um sujeito ético, ativo, solidário, empático, congruente, protagonista etc.), elementos passíveis de serem compreendidos como um investimento, mesmo que com menor ênfase, na demanda por formação humana desenvolvida pela escola.

Na construção dessa prática discursiva, salientamos o hibridismo entre diferentes e contraditórias matrizes teóricas, sendo as mais conflitantes: a Pedagogia do domínio de Bloom, com sua taxionomia dos processos cognitivos; e a teoria humanista, que mesmo não sendo evidenciada na BNCC, parece respaldar um investimento de formação socioemocional (aceitação positiva incondicional, empatia e tendência atualizante), sem, contudo, perder a referência sobre qualidades humanas necessárias ao trabalhador do século XXI. 
Nesse âmbito, é possível afirmar que, potencialmente, habilidades socioemocionais/competências socioemocionais são significações a serem construídas de forma mais aberta, por mais pessoas, gerando possibilidades de identificação. Isso pois não possuem uma referência fixa, uma construção pronta, parecem ter sido apensadas na instância da referida política curricular como suplementação a uma falta, que se refere sobretudo ao lugar da formação humana nessa proposta curricular.

Esperamos ter evidenciado o caráter horrífico que a crise educacional apresenta enquanto ameaça à intencionalidade formativa/educativa nas instituições escolares públicas, destacando o lugar da formação humana nessa lógica discursiva. Em resposta ao questionamento que motivou este trabalho, salientamos que há um considerável deslocamento entre as demandas humanistas formuladas para a educação entre as décadas finais do século passado e as quase duas décadas do século atual. Tal deslocamento é responsável pela necessidade de um "novo currículo” centrado na aprendizagem e no conhecimento, que facilmente se torna obsoleto, exigindo do estudante a capacidade de continuar aprendendo, tendência atualizante.

Há como projeção identitária, na referida proposta, um tipo de formação humana para um sujeito que consegue, mediante escolarização, assumir o lugar de sujeito competente cognitivo e emocionalmente. Para ele, parece haver a promessa de inserção em âmbitos como a universidade e o mundo/mercado do trabalho, condensação da razão de ser da escola, conforme evidenciam os projetos de vida e itinerários formativos.

A ambivalência desse discurso, em termos de política curricular, conecta o sujeito escolar a realidades de trabalho distintas, não deixando de considerar sua liberdade para escolher projetos e itinerários, mas deixando-o limitado ao processo de construção das escolhas possíveis no contexto da escola real.

O discurso sobre o vasto mundo do trabalho parece ser o meio de resgatar a cidadania desse tipo humano não escolarizado, mas que o será por meio da garantia dos direitos de aprendizagem, discurso que convida ao fortalecimento das problematizações sobre a performatividade, agora não mais restrita ao docente (Ball, 2005) e com consequências jurídicas, conforme assinala a lógica discursiva da educação como direito e a ausência de aprendizagem como negligência aos direitos de outrem.

Cidadania e formação humana, mesmo que não apresentadas nesses termos na BNCC, mostram-se presentes nos processos articulatórios que reclamam para a escola um espaço de humanização, tanto o é que as habilidades socioemocionais trazem elementos de uma psicologia humanista para construção de um sujeito competente em suas relações consigo mesmo e com o mundo, como procuramos evidenciar ao longo do trabalho. Esses significantes são elementos discursivos que se mostram vazios de uma significação plena, aceitando, portanto, sentidos por vezes contraditórios e complicados para uma proposta curricular diretiva como é o caso da BNCC.

Destarte, defendemos que a escola, enquanto projeto de sociedade, é lugar da promessa e de superação da barbárie, por isso, potente se faz firmá-la como lócus de formação de um sujeito, mas também como espaço de democratização de conhecimentos, sem, contudo, assumir uma compreensão rasa de aprender ligada a, tão somente, conteúdos/objetos de 
conhecimento expressos em habilidades ou ainda, de uma formação humana restrita à capacidade individual de lidar com as pressões do mundo do trabalho.

\section{Referências}

APPLE, Michael. W.; BEANE, J. A. O argumento por escolas democráticas. In: APPLE, Michael. W; BEANE, J. A. (org.). Escolas Democráticas. 2. Ed. São Paulo: Cortez, 2001.

APPLE, Michael. Ideologia e Currículo. 3. Ed. Porto Alegre: Artmed, 2006.

AUSUBEL, David. Paul. Psicología educativa: um punto de vista cognoscitivo. México: Editorial Trillas, 1976. Traducción al español de Roberto Helier D., de la primera edición de Educational psychology: a cognitive view.

BALL, Stephen J. Profissionalismo, gerencialismo e performatividade. Cad. Pesqui. [online]. 2005, vol.35, n.126, pp.539-564. ISSN 0100-1574.

BHABHA, Homi. K. O local da cultura. Belo Horizonte: Editora da UFMG, 2013.

BRASIL. Lei de Diretrizes e Bases da Educação Nacional 9394/93. Brasília, 1996.

BRASIL. Ministério da Educação. Base Nacional Comum Curricular. Brasília: MEC, 2017.

BRASIL. Ministério da Educação. Conselho Nacional de Educação. Resolução no 4, de 17 de dezembro de 2018.

BRASIL. Ministério da Educação. Guia de Implementação da Base Nacional Comum Curricular, Brasília, 2018.

BURITY, Joanildo. Psicanálise, identificação e a formação de atores coletivos. Disponível em: $<$ http://biblioteca.clacso.edu.ar/subida/Brasil/dipesfundaj/20121203021343/joan2.pdf >. Acesso em: 10 ago. 2013.

CANDAU, Vera Maria. A didática e a formação de educadores - Da exaltação à negação: a busca da relevância. In: CANDAU, V. M. (Org.) A didática em questão. Petrópolis: Vozes, 1983. p. 13- 24.

CHEMAMA, Roland. Dicionário de Psicanálise. Trad. Francisco Franke Setineri. Larousse, Porto Alegre: Artes médicas, 1995.

CLARKE, Mathew. Lacanian perspectives on education policy analysis. In: Kalervo, N. Gulson; Clarke, Mathew; Petersen, Eva Bendix. Education Policy and Contemporary Theory. London, Routledge, 2015. E-book.

FAURÉ, Edgar. International Commission on the Development of Education. Learning to be: the world of education today and tomorrow. Paris: UNESCO, 1972.

FREIRE, Paulo. A importância do ato de ler. São Paulo: Cortez, 1989.

GAUTHIER, Clermont; TARDIF, Maurice (Organizadores). A Pedagogia: teorias e práticas da Antiguidade aos nossos dias. Tradução de Lucy Magalhães; atualização da $3^{\circ}$ ed. Canadense: Guilherme João Freitas Teixeira. Petrópolis, RJ: Vozes, 2014.

GOLEMAN, Daniel. Trabalhando com a inteligência emocional. Rio de Janeiro: Objetiva, 1999.

LACLAU, Ernesto. A Razão Populista. Trad. Carlos Eugênio Marcondes de Moura. São Paulo: Três Estrelas, 2013.

LACLAU, Ernesto. A Teoria do Discurso de Ernesto Laclau: ensaios críticos e entrevistas. 1. ed. São Paulo: Annablume, 2015.

LACLAU, Ernesto. Discurso, 1993. Disponível em: <http://biblioteca.itam.mx/estudios/6089/68/ErnestoLaclauDiscurso.pdf>. Acesso em: 10 jan. 2015. 
LACLAU, Ernesto. Emancipação e Diferença. Rio de Janeiro: EdUERJ, 2011.

LACLAU, Ernesto. Misticismo, retórica y política. Buenos Aires: Fondo de Cultura Económica, 2000.

LACLAU, Ernesto. Nuevas reflexiones sobre la revolución de nuestro tiempo. Buenos Aires: Editora Nueva Visión, 1992.

LACLAU, Ernesto; MOUFFE, Chantal. Hegemonia e estratégia socialista: por uma política democrática radical. Trad. Joanildo A. Burity, Josias de Paula Jr. e Aécio Amaral. São Paulo: Intermeios; Brasília: CNPq, 2015.

LESSARD, Claude; CARPENTIER, Anylène. Políticas Educativas: a aplicação na prática. Tradução de Stephania Matousek, Petrópolis, RJ: Vozes, 2016.

LOPES, Alice Casimiro. Os parâmetros curriculares nacionais para o ensino médio e a submissão ao mundo produtivo: o caso do conceito de contextualização. Educ. Soc., Campinas, vol. 23, n. 80, setembro/2002, p. 386-400.

LOPES, Alice Casimiro. Discurso e Representação na Política de Currículo: o caso do ensino médio (20032010). Projeto: Rio de Janeiro, 2010.

LOPES, Alice Casimiro. Discurso nas Políticas de Currículo. Rio de Janeiro: Faperj, 2011.

LOPES, Alice Casimiro. Normatividade e intervenção política: em defesa de um investimento radical. In: LOPES, Alice Casimiro; MENDONÇA, Daniel (Org.). A Teoria do Discurso de Ernesto Laclau: ensaios críticos e entrevistas. 1. ed. São Paulo: Annablume, 2015. p. 117-147.

LOPES, Alice Casimiro. Políticas de currículo: questões teórico-metodológicas. In: Alice Casimiro Lopes; DIAS, Rosanne E.; ABREU, Rozana. (Org.). Discursos nas políticas de currículo. Rio de Janeiro: Quartet Editora/Faperj, 2011, v. 1, p. 19-44.

LOPES, Alice Casimiro. Política de currículo: recontextualização e hibridismo. Currículo sem Fronteiras, v. 5, n. 2, p. 50-64, 2005. Disponível em: <www.curriculosemfronteiras.org>. Acesso em: 15/ 06/ 2016.

LOPES, Alice Casimiro. Políticas de integração curricular. Rio de Janeiro: UERJ, 2008.

LOPES, Alice Casimiro. Por um currículo sem fundamentos. Linhas Críticas, Brasília, DF, v. 21, n. 45, p. 445-466, mai./ago. $2015 . \quad$ Disponível em: $<$ http://periodicos.unb.br/index.php/linhascriticas/article/view/16735/11881>. Acesso em: 30 jan. 2017.

LOPES, Alice Casimiro. Teorias Pós-críticas, Política e Currículo. Educação, Sociedade \& Culturas, v. 39, p. 7-23, 2013. Disponível em: <http://www.fpce.up.pt/ ciie/?q=publication/revistaeduca\%C3\%A7\%C3\%A3o-sociedade-culturas/edition/ educa\%C3\%A7\%C3\%A3o-sociedade-culturas39>. Acesso em: 3 fev. 2017.

LOPES, Alice Casimiro. Teorias Pós-críticas, Política e Currículo. In: Dossiê Temático: Configurações da Investigação Educacional no Brasil, 2013. Disponível em: $<$ http://www.fpce.up.pt/ciie/sites/default/files/02.AliceLopes.pdf>. Acesso em: 24 jan. 2015.

LOPES, Alice Casimiro. Sentidos de qualidade na política de currículo (2003-2012). Educação e Realidade, Porto Alegre, v. 39, p. 337-357, abr./jun. 2014.

LOPES, Alice. C.; ALBA, Alícia de. (Org.). Diálogos Curriculares entre Brasil e México. Rio de Janeiro: EdUERJ, 2014.

LOPES, Alice C.; CUNHA, Erika V. R. da; COSTA, Hugo H. C. Da recontextualização à tradução: investigando políticas do currículo. Currículo sem Fronteiras, v. 13, n. 3, p. 392-410, 2013.

LOPES, Alice. C.; MACEDO, Elizabeth. (Org.). Currículo: debates contemporâneos. 2. ed. São Paulo: Cortez, 2005.

LOPES, Alice. C.; MACEDO, Elizabeth. Nota Introdutória - Cultura e Política: implicações para o Currículo. Currículo sem Fronteiras, v. 9, n. 2, pp.5-10, jul./dez. 2009

LOPES, Alice. C.; MACEDO, Elizabeth. Teorias de Currículo. São Paulo: Cortez, 2011. 
MASLOW, A. Introdução à psicologia do ser. Rio de Janeiro: Eldorado, 1962.

PACHECO, José A. Currículo: entre teorias e métodos. Cadernos de Pesquisa, v. 39, n. 137, p. 383-400, mai./ago. 2009.

POPKEWITZ, Thomas. Números em grades de inteligibilidade: dando sentido à verdade educacional. In: TURA, Maria de Lourdes Rangel; GARCIA, Maria Manuela Alves (Orgs.). Currículo, políticas e ação docente. Rio de Janeiro: Editora da Universidade do Estado do Rio de Janeiro, 2013, p. 19-50.

QUINET, Antonio. A descoberta do inconsciente: do desejo ao sintoma. Rio de Janeiro: Zahar, 2011.

SAUSSURE, Ferdinand (1916). Curso de linguística geral. 26. ed. São Paulo: Cultrix, 2004.

TADEU, Tomaz; MOREIRA, Antônio F. (Orgs.). Currículo, cultura e sociedade. 12. ed. São Paulo: Cortez, 2013.

\section{Correspondência}

Geniana dos Santos - Doutora em Educação pela Universidade do Estado do Rio de Janeiro - UERJ, Licenciada em Letras e em Pedagogia. Atua como docente na Universidade Federal de Mato Grosso - UFMT

ORCID: https://orcid.org/0000-0001-6926-0132

E-mail: genianacba@gmail.com

Denise de Souza Destro: Doutora em Educação pela Universidade do Estado do Rio de Janeiro - UERJ, Licenciada em Educação Física pela Universidade Federal de Juiz de Fora. Atua na Rede Municipal de Educação em Juiz de Fora, Minas Gerais.

ORCID: 0000-0002-0372-3138

E-mail: denisesdestro@gmail.com

Texto publicado em Currículo sem Fronteiras com autorização das autoras 